\title{
Comportamento Ingestivo Diurno de Novilhos em Pastejo Submetidos a Níveis Crescentes de Suplementação Energética ${ }^{1}$
}

\author{
René Mauricio Patiño Pardo ${ }^{2}$, Vivian Fischer ${ }^{3}$, Maira Balbinotti ${ }^{4}$, Claiton Baes Moreno ${ }^{5}$, \\ Everson Xavier Ferreira ${ }^{6}$, Ricardo Irigon Vinhas ${ }^{7}$, Pedro Lima Monks ${ }^{8}$
}

\begin{abstract}
RESUMO - O objetivo deste trabalho foi observar o comportamento ingestivo de novilhos de corte em pastejo submetidos a diferentes níveis de suplementação energética. Foram utilizados 38 novilhos de raça não definida, de 12 a 15 meses de idade, com peso médio de $159,97 \mathrm{~kg}$. Os animais foram mantidos sob pastejo contínuo em uma pastagem nativa melhorada com Lotus subbiflorus e invadida por Eragrostis planna Ness. Dois níveis de sorgo moído foram fornecidos como suplemento energético e os tratamentos consistiram de: controle (T0), sem suplemento; 0,75\% do peso vivo (T0.75) e 1,5\% do peso vivo (T1.5). Os animais foram distribuídos aleatoriamente aos tratamentos, segundo um delineamento inteiramente casualizado e avaliados durante quatro períodos. Na média geral do experimento, os tempos diurnos de pastejo ( $\mathrm{PA})(\mathrm{P}=0,0059)$, ruminação total ( $\mathrm{RT})(\mathrm{P}=0,0013)$ e caminhada $(\mathrm{P}=0,0076)$ variaram de forma quadrática, com os níveis de suplementação apresentando os maiores valores para, respectivamente, controle, T0.75 e T1.5. O tempo de descanso (DT) aumentou linearmente com o incremento dos níveis de suplemento ( $\mathrm{P}=0.0001)$. A taxa de bocados e o número total de bocados variaram, respectivamente, de forma linear $(\mathrm{P}=0,0001)$ e quadrática $(\mathrm{P}=0,0002)$, com o aumento nos níveis de suplementação. Não foram encontradas diferenças para estações alimentares visitadas por minuto e tempo de permanência no cocho entre os tratamentos.
\end{abstract}

Palavras-chave: descanso, pastagem nativa melhorada, pastejo, sorgo moído, ruminação

\section{Diurnal Ingestive Behavior of Grazing Steers Fed Increasing Levels of Energy Supplementation}

\begin{abstract}
The trial aimed to observe the ingestive behavior of grazing beef steers submitted to different energetic supplementation levels and kept under an improved natural pasture. Thirty eight beef steers without definite breed, aging 12 to 15 months and weighing 159,97 kg were used. Animals were kept under set stocking in a natural pasture improved with Lotus Subbiflorus and invaded with Eragrostis plana Ness. Two levels of ground sorghum grain were offered as an energetic supplement, and treatments consisted of control or without supplement (T0); 0,75\% of mean live weight (T0.75), 1,5\% of mean live weight (T0.75). Animals were randomly assigned to treatments according to a complete randomized design. Considering the overall mean, diurnal grazing time $(\mathrm{P}=0.0059)$, total rumination time $(\mathrm{P}=0.0013)$ and walking time $(\mathrm{P}=0.0076)$ followed by a quadratic trend in relation to the supplement levels, and showed larger values for control, $\mathrm{T} 0.75$ and T1.5, respectively. Diurnal idling followed a positive linear trend with increasing supplementation levels $(\mathrm{P}=0.0001)$. Biting rate and total bites number followed linear $(\mathrm{P}=0.0001)$ and quadratic trends $(\mathrm{P}=0.0002)$, respectively, with increasing supplementation levels. There were no differences for feeding stations visited per minute and for time spent at the trough between treatments.
\end{abstract}

Key Words: grazing, idling, improved rangeland, rumination, sorghum grain

\section{Introdução}

O Rio Grande do Sul possui um rebanho bovino de corte de aproximadamente 9,8 milhões de cabeças, cerca de $80 \%$ do total do estado, das quais 1,5 milhões correspondem a animais entre 1 e 2 anos de idade, distribuídos em cerca de 12 milhões de hectares de pastagens nativas e cultivadas. Essas pasta- gens representam aproximadamente $53 \%$ da superfície total do Estado, constituindo-se na principal fonte de alimento da população bovina e ovina (IBGE, 1998).

Um dos objetivos básicos de todo sistema de produção de bovinos em pastagem é cobrir as necessidades nutricionais dos animais durante todo o ano, mantendo uma oferta permanente de alimento em

\footnotetext{
${ }^{1}$ Pesquisa financiada pela FAPERGS, PPGZ-UFPEL e Parceria agropecuária Piratini.

${ }^{2}$ Zootecnista, Mestre em Produção animal pela PPGZ-UFPEL, residente na Colômbia. E.mail: re_patino@yahoo.com

${ }^{3}$ D.S. Produção Animal, Professor Adjunto Departamento de Zootecnia UFPEL, Bolsista CNPq, Pelotas - RS - CEP: $96010-970$. E.mail: vfried@portoweb.com.br; vfried@ufpel.tche.br

${ }^{4}$ Aluno curso de doutorado PPGZ - UFPEL. E.mail: mairab22@ufpel.tche.br

${ }^{5}$ Aluno do curso de medicina veterinária, bolsista de Iniciação Científica FAPERGS.

${ }^{6}$ Aluno do curso de medicina veterinária, bolsista de Iniciação Científica CNPq.

${ }^{7}$ Produtor rural, Parceria Agropecuária Piratini, Pelotas, RS.

8 D.S., Produção Vegetal, Professor Adjunto DZ - FAEM - UFPEL. E.mail: plmonks@ufpel.tche.br
} 
quantidade e qualidade suficientes, para obter ótima resposta produtiva por parte dos animais. Todavia, nas condições de pastagem nativa, existem grandes variações na produção de matéria seca e na qualidade da pastagem nativa, afetando negativamente a produtividade animal (Correa, 1993; Moojen, 1991).

Algumas alternativas vêm sendo utilizadas para minimizar os efeitos desta problemática, principalmente nas épocas em que a produção de forragem é mais drasticamente afetada, como são as estações de outono e inverno, como a suplementação, a qual pode permitir maiores ganhos de peso por animal e por área (Rocha, 1999).

Um sistema de bovinos a pasto caracteriza-se por uma complexa e numerosa quantidade de fatores e suas interações, os quais, por sua vez, afetam o comportamento ingestivo dos animais a pasto e, conseqüentemente, o seu desempenho e a rentabilidade da empresa. Os ruminantes podem modificar um ou mais componentes do seu comportamento ingestivo para superar condições limitantes ao consumo e obter as quantidades de nutrientes necessárias à mantença e produção (Forbes, 1988).

Na literatura, encontram-se efeitos variáveis da suplementação sobre o comportamento ingestivo dos animais (Karsly, 2001). Barton et al. (1992) e Adams (1985) estudaram o efeito do horário de fornecimento da suplementação sobre o comportamento ingestivo de animais a pasto. Barton et al. (1992) relataram que o horário de suplementação com caroço de algodão não afetou os tempos de pastejo, ruminação ou caminhada. Porém, Adams (1985) constatou alterações na atividade normal de pastejo de novilhos de corte, quando suplementados com grão de milho. As alterações provocadas nos animais poderiam também causar efeitos sobre as características das pastagens. Torna-se necessário realizar estudos para esclarecer o efeito da suplementação sobre o comportamento animal em pastejo e seus possíveis reflexos sobre os atributos da pastagem e sobre o desempenho animal.

Este trabalho foi conduzido com o objetivo de avaliar o comportamento ingestivo diurno de novilhos em pastejo, quando submetidos a diferentes níveis de suplementação energética, sobre uma pastagem nativa melhorada com a inclusão de cornichão “El Rincón” (Lotus subbiflorus) e invadida por capim anonni 2 (Eragrostis planna Ness).

\section{Material e Métodos}

O experimento foi realizado em propriedade particular da Parceria Agropecuária Piratini, situada no município de Cerrito, sudoeste do Rio Grande do Sul, de 11/08/00 a 19/12/00, totalizando quatro períodos de avaliação de 28, 35, 33 e 33 dias.

A área total do experimento foi de aproximadamente 17,5 ha, dividida em três potreiros de 5,8, 5,7 e 6,3 ha. A temperatura e precipitação pluviométrica médias mensais, durante a fase experimental, foram $15,3^{\circ} \mathrm{C}$ e $168 \mathrm{~mm}$, respectivamente.

Foram utilizados 38 novilhos de corte sem raça definida, provenientes de cruzamentos entre raças européias Hereford, Aberdeen Angus e Charolês, com aproximadamente 12 a 15 meses de idade, com um peso vivo inicial de 159,97 $\pm 16,24 \mathrm{~kg}$. Os animais foram mantidos em uma pastagem nativa melhorada com a sobressemeadura de cornichão “El Rincón” e invadida, em grande parte, por capim annoni 2. Os novilhos foram distribuídos aleatoriamente aos tratamentos.

A pastagem nativa foi composta predominantemente por grama tapete (Axonopus affinis Chase) e grama forquilha (Paspalum notatum Flügge), além da presença de grama seda (Cynodon dactylon). Foi utilizado o pastejo contínuo com lotação variável. Os animais foram manejados em três grupos inicialmente de 13 animais em cada lote, porém um dos animais adoeceu, durante o primeiro período experimental, e foi retirado do experimento. Os dados relativos a este animal não foram considerados nas análises. Destinou-se um potreiro para cada grupo. Durante a condução do experimento, manteve-se um resíduo médio de forragem de 5 a $8 \mathrm{~cm}$ de altura, carga animal inicial aproximada de $345,5 \mathrm{~kg} / \mathrm{ha}$, uma oferta inicial de matéria seca (DISPMS) de 1388,8 kg, uma oferta inicial de matéria seca verde (DISPMSV) de 721,8 kg e oferta diária de forragem aproximadamente de $20 \mathrm{~kg}$ de MS por cada $100 \mathrm{~kg}$ de peso vivo. Além dos animais testados, foram utilizados outros três, como reguladores da carga, utilizando-se como critério a manutenção de oferta de forragem semelhantes nos três tratamentos.

Dois níveis de sorgo moído foram testados como suplemento energético e os tratamentos consistiram de controle ou sem suplemento (T0); 0,75\% do peso vivo de suplemento (T0.75) e 1,5\% do peso vivo de suplemento (T1.5). O suplemento foi fornecido diariamente às $14 \mathrm{~h}$, em cochos de madeira nos potreiros, 
com um espaço linear de $45 \mathrm{~cm}$ por animal, com livre acesso à água e sal mineral. No dia seguinte, os cochos eram limpos e verificadas as sobras antes do novo fornecimento. A partir do início do terceiro período, os animais suplementados receberam 40 gramas de uréia por cada $100 \mathrm{~kg}$ de peso vivo, devido à reduzida participação do cornichão na pastagem disponível.

O comportamento animal foi avaliado, visualmente, por um observador para cada lote, durante dois dias por período: ao final da primeira e terceira semana de cada período experimental, das 8:40 às 18 h (560 minutos), totalizando oito dias de observações durante o experimento. As atividades comportamentais foram observadas em cinco animais por lote (40\% do lote), escolhidos por facilidade de identificação. $\mathrm{O}$ tempo gasto por animal nas atividades de pastejo (PA), comendo no cocho (COCHO), ruminando (RT), descansando (DT) e caminhando (CA), foi estimado a partir de observações realizadas a cada cinco minutos. As observações foram feitas com a ajuda de binóculos e em dias sem precipitação pluviométrica. A atividade de pastejo também foi medida como a porcentagem dos animais de cada grupo suplementado ( $\mathrm{n}=5$ em cada grupo) que se encontravam na atividade, e os valores foram comparados com aqueles obtidos considerando-se todos os animais suplementados, para verificar a correlação entre estas medidas.

As atividades comportamentais foram consideradas como mutuamente excludentes, ou seja, a cada registro, cada um dos animais foi classificado em apenas uma atividade. A atividade de pastejo incluiu o tempo gasto na seleção dos sítios de pastejo, apreensão e manipulação do bolo alimentar. Breves deslocamentos com a cabeça baixa à procura de pasto foram computados como tempo de pastejo. O descanso considerou o tempo em que os animais não mostravam atividade de locomoção ou movimentos mandibulares. A atividade de ruminação considerou os tempos gastos na regurgitação e remastigação dos bolos e o tempo decorrido entre a deglutição e a regurgitação. A caminhada considerou o tempo gasto pelos animais ao se locomoverem pelo potreiro, com a cabeça erguida.

Durante o terceiro e quarto períodos, nos mesmos dias de avaliação do comportamento, foram registrados o número de bocados por minuto (taxa de bocados -TXBOC) e o número de estações alimentares (EST) visitadas por minuto, segundo o método de Ruyle \& Dwyer (1985). Esses autores consideraram como estação alimentar um semicír- culo hipotético disponível em frente ao animal que ele alcançaria sem que movesse suas patas dianteiras. Desta forma, durante a atividade de pastejo, considerou-se que o animal mudava de uma estação alimentar para outra sempre que este movimentava as patas dianteiras para continuar a pastejar. Realizaram-se três observações, com duração de um minuto cada, em três momentos do dia (início da manhã, meio dia e final da tarde), sobre os mesmos cinco animais avaliados quanto às demais atividades comportamentais, totalizando nove observações por animal e por dia. Calculou-se a média do número de estações alimentares por animal e por dia. O número total de bocados (TOBOC) foi calculado por meio da multiplicação da taxa média de bocados pelo tempo de pastejo diurno.

Foi determinada a quantidade de pastagem de cada potreiro ao início e final de cada período. Foi utilizado o método de avaliação visual com padrões de 1 a 5 (Haydock \& Shaw, 1975), em que 1 correspondeu à área de menor disponibilidade de forragem e 5, à de maior. Os cortes destes cinco padrões foram feitos ao nível do solo com tesouras de esquilar, com um quadrado de $0,25 \mathrm{~m}^{2}$. Foram realizadas entre 50 e 55 avaliações visuais por potreiro. As amostras obtidas foram secas em estufa com ventilação forçada a $60^{\circ} \mathrm{C}$ por 48 horas e pesadas, determinando assim a porcentagem de MS do material para os cálculos posteriores.

Foram determinadas a proporção de material verde e morto e a composição florística, realizando duas amostragens, no início e na metade de cada período experimental. Foram cortadas entre 35 e 40 subamostras por potreiro por vez para formar duas amostras compostas, usando um círculo de $0,088 \mathrm{~m}^{2}$. Destinou-se uma amostra para a determinação dos componentes vivo e morto e a outra para determinação de espécies, separando-os manualmente, com a amostra ainda fresca. As amostras foram secas em estufa com ventilação forçada a $60^{\circ} \mathrm{C}$ por 48 horas, pesadas e, posteriormente, realizados os cálculos de percentagens em base seca. A quantidade de matéria seca verde da pastagem foi calculada multiplicando-se a a sua quantidade de matéria seca pela porcentagem de material verde.

Foi determinada a composição química da pastagem disponível e daquela obtida por simulação de pastejo. Porcentagens de matéria seca (MS), cinzas (C), matéria orgânica (MO) e proteína bruta (PB) foram determinadas segundo AOAC (1975); as porcentagens de fibra em detergente neutro (FDN) e fibra em detergente ácido (FDA), segundo 
metodologia de Goering \& Van Soest, (1970). Análises de digestibilidade in vitro da matéria seca (DIVMS) e da matéria orgânica (DIVMO) para as amostras obtidas por simulação de pastejo seguiu a metodologia de Tilley \& Terry (1963). A colheita destas amostras foi realizada com um número variável de amostras colhidas manualmente, durante a atividade de pastejo, próximo aos locais pastejados pelos animais. Em cada período experimental, estas amostras foram coletadas durante dois dias, um no final da primeira semana e outro no final terceira semana.

Os dados relativos às temperaturas mínima, média e máxima se encontram na tabela 1 .

Foi adotado o delineamento inteiramente casualizado, onde cada animal representou uma repetição. Em cada período experimental, os atributos do comportamento, exceto o tempo comendo no cocho, foram submetidos à análise de regressão, considerando os seus componentes lineares e quadráticos, usando o procedimento REG do SAS (1989). Os valores de probabilidade apresentados referem-se aos dos testes dos parâmetros da regressão de grau mais elevado significativo $\left(\mathrm{Ho}_{\mathrm{i}} \mathrm{b}_{\mathrm{i}}=0\right)$ e o nível de significância adotado para a rejeição da hipótese de nulidade foi de 0,05 . O valor de $\mathrm{R}^{2}$ refere-se ao modelo testado. O tempo comendo no cocho, medido nos tratamentos suplementados, foi submetido à análise da variância, em cada período. Os atributos químicos e produtivos das pastagens em cada período experimental foram expostos descritivamente, em função do período de amostragem e tratamento. A análise de correlação foi realizada usando o procedimento CORR Pearson do SAS (1989), relacionando os valores médios mensais dos atributos dos cinco animais com os valores das temperaturas média, mínima e máxima, totalizando 60 pares de valores.

Tabela 1 - Dados médios da temperatura máxima, mínima e média $\left({ }^{\circ} \mathrm{C}\right)$, durante os dias de avaliação de comportamento para cada período

Table 1 - Means of maximal, minimal and mean temperature, on behavior evaluation days for each period $\left({ }^{\circ} \mathrm{C}\right)$

\begin{tabular}{|c|c|c|c|c|}
\hline \multirow[t]{2}{*}{$\begin{array}{l}\text { Temperatura }\left({ }^{\circ} \mathrm{C}\right) \\
\text { Temperature }\left({ }^{\circ} \mathrm{C}\right)\end{array}$} & \multicolumn{4}{|c|}{$\begin{array}{l}\text { Períodos } \\
\text { Periods }\end{array}$} \\
\hline & 1 & 2 & 3 & 4 \\
\hline $\begin{array}{l}\text { Mínima } \\
\text { Minimal }\end{array}$ & 9,5 & 10,7 & 13,8 & 15,7 \\
\hline & 15,5 & 14,6 & 18,1 & 22,0 \\
\hline $\begin{array}{l}\text { Máxima } \\
\text { Maximal }\end{array}$ & 20,8 & 18,1 & 23,3 & 27,4 \\
\hline
\end{tabular}

R. Bras. Zootec., v.32, n.6, p.1408-1418, 2003

\section{Resultados e Discussão}

Na Tabela 2, são apresentadas as equações de regressão que relacionam os atributos comportamentais aos níveis de sorgo em cada período experimental e na média geral do experimento. Na Figura 1, são apresentadas os tempos diurnos de pastejo, ruminação total, descanso total e caminhada observados em cada tratamento nos quatro períodos experimentais e as médias gerais do experimento.

No primeiro período, observa-se que o tempo de pastejo diminuiu linearmente conforme os níveis de suplementação aumentaram, enquanto, nos demais períodos, observou-se que o PA variou de forma quadrática segundo os níveis do suplemento (Tabela 2; Figura 1). Os pontos críticos do tempo de pastejo dados em função da quantidade de suplemento foram de 0,$63 ; 1,13 ; 1$,33 e 1,37\% do peso vivo, respectivamente para os períodos 2, 3, 4 e na média geral do experimento, evidenciando o efeito depressor do suplemento energético sobre o tempo de pastejo diurno. Considerando a média geral do experimento, verifica-se que a quantidade crítica de suplemento foi semelhante àquela fornecida pelo nível mais alto de suplementação. Esse resultado pode indicar a ocorrência do efeito de substituição de grão por pastagem, como relatado por Restle et al. (1999) e Minson (1990). Barton et al. (1992) constataram que novilhos suplementados diminuíram em 1,5 horas o tempo de pastejo em comparação ao grupo controle. Bailey et al. (1974) também verificaram que novilhos Holandês recebendo $3,6 \mathrm{~kg}$ de aveia reduziram o tempo de pastejo em 2 horas. Fischer et al. (2002) também observaram redução do tempo de pastejo diurno de 409 para 343 minutos de novilhas Jersey mantidas em azevém anual (Lolium multiflorum), que receberam milho moído na quantidade equivalente a $1 \%$ do PV em relação às não suplementadas.

Este resultado também está de acordo com os de Gonçalves (2001), os quais encontraram os seguintes valores para o tempo de pastejo: 530, 380, 433, 395, 332 minutos/dia, respectivamente para os tratamentos controle, $0,5,1,1,5$ e $2 \%$ de farelo de arroz, e atribuíram o decréscimo no tempo de pastejo observado nos tratamentos suplementados em relação ao controle ao efeito substitutivo que a suplementação teve em relação ao consumo de campo nativo.

As diferenças do tipo de relação entre o tempo de pastejo e os níveis de suplemento, linear no primeiro período e quadrática nos demais, podem estar relacionadas às características florísticas e químicas da 
Tabela 2 - Equações de regressão para as atividades diurnas de comportamento, tempos de: pastejo (PA), ruminação total (RT), descanso total (DT) e caminhada (CA) em função dos níveis de suplemento energético (X, em porcentagem do peso vivo) para cada período

Table 2 - Regressions equations for diurnal time spent grazing (G), ruminating (TR), idling (TI) and walking (W), according to the energy supplements levels ( $X$ as live weight percentage) at each period

\begin{tabular}{|c|c|c|c|}
\hline $\begin{array}{l}\text { Atividade } \\
\text { Activity }\end{array}$ & $\begin{array}{l}\text { Equações de regressão } \\
\text { Regression equations }\end{array}$ & $\mathrm{r}^{2} / \mathrm{R}^{2 *}$ & Ho: $b_{i}=0$ \\
\hline & $\begin{array}{c}\text { Período } 1 \text { (11/08 a 6/09) } \\
\text { Period } 1\end{array}$ & & \\
\hline PA (G) & $Y=381,75-62,33 X$ & 0,66 & 0,0002 \\
\hline $\mathrm{RT}(\mathrm{TR})$ & $Y=69+60,33 X-49,33 X^{2}$ & 0,53 & 0,0094 \\
\hline $\mathrm{DT}(T I)$ & $Y=82,50-73,67 X+81,33 X^{2}$ & 0,58 & 0,0315 \\
\hline \multirow[t]{2}{*}{ CA $(W)$} & $Y=13,42+10,33 X$ & 0,40 & 0,0108 \\
\hline & $\begin{array}{c}\text { Período } 2(7 / 09 \text { a } 12 / 10) \\
\text { Period } 2\end{array}$ & & \\
\hline $\operatorname{PA}(G)$ & $Y=402,5-192,33 X+66,22 X^{2}$ & 0,83 & 0,0433 \\
\hline $\mathrm{RT}(T R)$ & $Y=86,50$ & & \\
\hline $\mathrm{DT}(\mathrm{TI})$ & $Y=57,08+48,33 X$ & 0,67 & 0,0002 \\
\hline \multirow[t]{2}{*}{$\mathrm{CA}(W)$} & $Y=21,50-23,00 X+20,89 X^{2}$ & 0,44 & 0,0445 \\
\hline & $\begin{array}{c}\text { Período } 3(13 / 10 \text { a } 14 / 11) \\
\text { Period } 3\end{array}$ & & \\
\hline PA (G) & $Y=397-303,66 X+134,67 X^{2}$ & 0,90 & 0,0002 \\
\hline $\mathrm{RT}(\mathrm{TR})$ & $Y=110+105 X-73,33 X^{2}$ & 0,65 & 0,0005 \\
\hline DT (TI) & $Y=35+48,67 X$ & 0,69 & 0,0001 \\
\hline \multirow[t]{3}{*}{ CA $(W)$} & $Y=10,5+38,33 X-24,44 X^{2}$ & 0,77 & 0,0001 \\
\hline & Período 4 (15/11 a 19/12) & & \\
\hline & Period 4 & & \\
\hline $\mathrm{PA}(G)$ & $Y=297,5-173,67 X+65,33 X^{2}$ & 0,91 & 0,0026 \\
\hline $\mathrm{RT}(\mathrm{TR})$ & $Y=156,83-30,67 X$ & 0,61 & 0,0006 \\
\hline $\mathrm{DT}(T I)$ & $Y=38,5+149,67 X-52,89 X^{2}$ & 0,81 & 0,0417 \\
\hline \multirow[t]{3}{*}{ CA $(W)$} & $Y=23-36 X+37,33 X^{2}$ & 0,96 & 0,0001 \\
\hline & Média geral & & \\
\hline & Overall mean & & \\
\hline $\operatorname{PA}(G)$ & $Y=369,75-183,5 X+66,89 X^{2}$ & 0,90 & 0,0059 \\
\hline $\mathrm{RT}(\mathrm{TR})$ & $Y=101,38+60,67 X-47,78 X^{2}$ & 0,66 & 0,0013 \\
\hline $\mathrm{DT}(T I)$ & $Y=51,94+53,92 X$ & 0,79 & 0,0001 \\
\hline CA $(W)$ & $Y=17,50-5,75 X+10,56 X^{2}$ & 0,83 & 0,0076 \\
\hline
\end{tabular}

${ }^{*} \mathrm{r}^{2} / \mathrm{R}^{2}=$ Coeficiente de determinação (Coefficient of determination).

pastagem (Tabela 3).

No primeiro período, podem-se observar valores numericamente superiores de material morto e FDN, mas valores inferiores de proteína bruta em relação aos demais períodos, indicando qualidade inferior da pastagem disponível neste período, o que pode ter contribuído para dificultar a apreensão da forragem verde pelos animais, desestimulando o pastejo, sobretudo, no nível mais elevado de suplementação.

A desfoliação progressiva de uma pastagem, com a conseqüente redução na densidade de folhas verdes, provocou diminuição no apetite da animais, com redução do tamanho do bocado e posteriormente com diminuição do número de bocados e do tempo de pastejo (Chacon \& Stobbs, 1976).

Observa-se a maior participação na atividade de

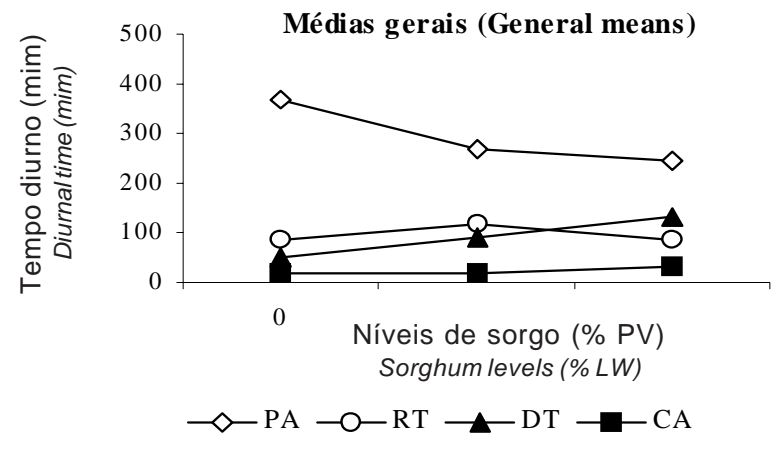

Figura 1 - Comportamento descritivo para os tempos diurnos de pastejo (PA), ruminação total (RT), descanso (DT) e caminhada (CA), de acordo com os níveis de suplementação.

Figure 1 - Descriptive behavior for diurnal times spent grazing, ruminating, idling and walking, according to the supplementation levels. 
pastejo diurno pelos animais controle em relação aos suplementados. As porcentagens médias do tempo diurno de pastejo com relação ao tempo avaliado foram aproximadamente de 66, 48 e 44\%, respectivamente para os grupos controle, 0,75 e 1,5\% de suplemento (Figura 2).

Gonçalves (2001) encontrou que o tempo de pastejo de novilhos que receberam $0,0,5,1,1,5$ e 2\% do PV de farelo de arroz integral representou, respectivamente, uma proporção de 37, 26, 30, 27 e 23\% das 24 horas de observação efetuadas.

Na Figura 2, pode-se apreciar a distribuição diurna de pastejo para cada um dos tratamentos avaliados.

A distribuição horária da porcentagem de animais em pastejo do tratamento controle foi mais uniforme durante o período diurno comparada com as dos animais suplementados. Este resultado concorda com os de Farinatti (2002), que avaliou o comportamento de ovinos sem suplementação ou então recebendo suplementação energética ou protéica.

Foi observada correlação de 0,97 entre as porcentagens dos cinco animais que pastavam a cada observação com relação à porcentagem do total de animais pastejando (13, 12 e 13, respectivamente para os lotes que receberam os tratamentos controle, 0,75 e $1,5 \%$ de suplemento). Pode-se inferir que os cinco animais representaram confiavelmente o seu grupo quanto ao tempo de pastejo.

Apesar de a análise da variância ter sido realizada considerando os dados relativos a cada período experimental, pode-se verificar que o tempo diurno de pastejo foi relativamente semelhante nos primeiros três períodos experimentais, diminuindo acentuadamente no quarto período de avaliação, provavelmente devido à ação negativa da temperatura ambiente (Tabela 4). Os valores médios dos tempos diurnos de pastejo foram 335, 320, 296 e 229 minutos, respectivamente para os períodos $1,2,3$ e 4 . As altas temperaturas apresentadas nos dias de observação durante quarto período, com uma média de $27,4^{\circ} \mathrm{C}$ para a temperatura máxima, podem ter causado esta diminuição no PA. Este efeito pode ser estimado através da seguinte equação: $Y=597,81-83,17 X_{1}$ $-13,71 X_{2}, R^{2}=0,86$, em que $Y$ corresponde ao tempo de pastejo diurno; $\mathrm{X}_{1}$, ao nível de suplemento; e $\mathrm{X}_{2}$, à temperatura média.

Houve possível deslocamento do pastejo diurno para o período noturno. Forbes (1995) relatou aumento na atividade de pastejo noturno no verão. Krysl \& Hess (1993) concluíram que fatores como temperatura, nível de suplementação e manejo da pastagem influenciam o tempo diário de pastejo.

Nos períodos 1 e 3, a ruminação total (RT) comportou-se de forma quadrática em relação aos níveis de suplementação, e os pontos críticos foram 0,61 e $0,72 \%$ do PV, respectivamente. No entanto, no período 2, o seu valor permaneceu constante independente do nível de suplementação ministrado. Já no período 4, houve decréscimo linear do RT, conforme se passou do controle para os demais níveis de suplementação. Considerando a média geral do experimento, o RT se comportou de forma quadrática em relação aos níveis de suplementação, e seu ponto crítico correspondeu a 0,63\% do PV (Tabela 2; Figura 1).

Tabela 3 - Valores médios da percentagem de matéria seca (MS), cinzas, proteína bruta (PB), fibra em detergente neutro (FDN), fibra em detergente ácido (FDA) e da porcentagem de material morto (Morto) na pastagem disponível, por tratamento e por período

Table 3 - Mean values of dry matter (DM), crude protein (CP), neutral detergent fiber (NDF), acid detergent fiber (ADF) percentages and percentage of dead material(DEAD) of the available pasture per treatment and period

\begin{tabular}{|c|c|c|c|c|c|c|c|}
\hline $\begin{array}{l}\text { Tratamento } \\
\text { Treatment }\end{array}$ & $\begin{array}{c}\text { Período } \\
\text { Period }\end{array}$ & $\begin{array}{l}\text { MS } \\
D M\end{array}$ & $\begin{array}{c}\text { Cinzas } \\
\text { Ash }\end{array}$ & $\begin{array}{l}\mathrm{PB} \\
C P \\
\end{array}$ & $\begin{array}{l}\text { FDN } \\
N D F\end{array}$ & $\begin{array}{l}\text { FDA } \\
A D F\end{array}$ & $\begin{array}{l}\text { Morto } \\
D E A D\end{array}$ \\
\hline 0 & 1 & 40,01 & 9,62 & 9,27 & 68,24 & 35,57 & 44,1 \\
\hline 0 & 2 & 40,33 & 10,96 & 9,16 & 71,03 & 36,95 & 34,5 \\
\hline 0 & 3 & 25,25 & 10,96 & 14,52 & 58,23 & 31,63 & 25,1 \\
\hline 0 & 4 & 26,28 & 10,38 & 13,17 & 60,15 & 41,84 & 19,3 \\
\hline $0,75 \%$ & 1 & 42,67 & 11,33 & 8,67 & 68,87 & 37,79 & 50,0 \\
\hline $0,75 \%$ & 2 & 42,07 & 11,65 & 8,69 & 70,41 & 39,42 & 39,0 \\
\hline $0,75 \%$ & 3 & 25,86 & 13,84 & 14,47 & 60,48 & 33,66 & 21,7 \\
\hline $0,75 \%$ & 4 & 28,71 & 9,77 & 11,90 & 64,77 & 40,45 & 19,38 \\
\hline $1,5 \%$ & 1 & 43,04 & 12,74 & 8,89 & 68,28 & 37,38 & 50,5 \\
\hline $1,5 \%$ & 2 & 46,98 & 11,83 & 7,38 & 73,20 & 40,04 & 44,3 \\
\hline $1,5 \%$ & 3 & 25,58 & 12,56 & 12,72 & 58,78 & 32,55 & 26,0 \\
\hline $1,5 \%$ & 4 & 28,72 & 9,30 & 12,10 & 60,55 & 40,70 & 19,75 \\
\hline
\end{tabular}



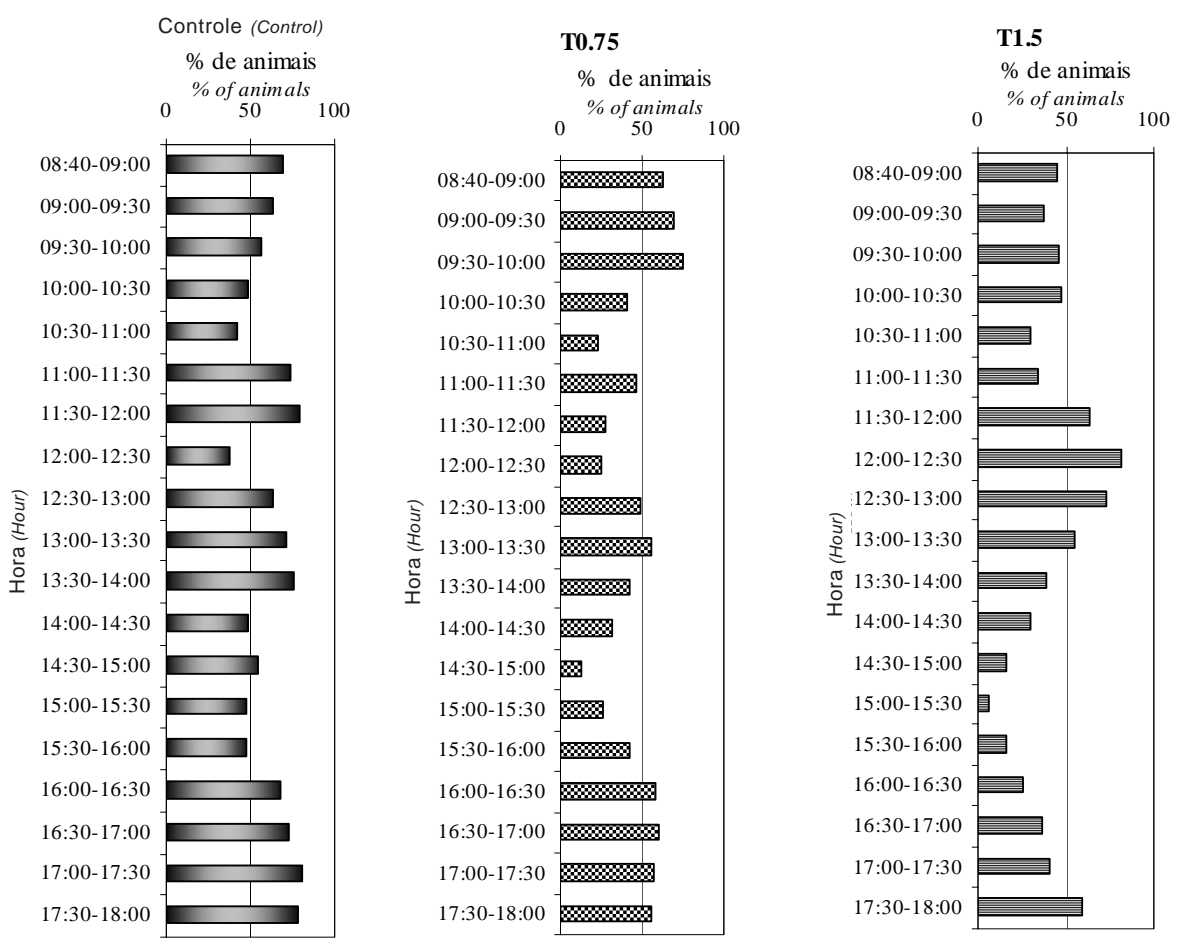

Figura 2 - Distribuição horária da atividade de pastejo para cada tratamento (valores como \% do lote envolvido na atividade, valores médios do experimento).

Figure 2 - Hourly distribution of grazing activity for each treatment (values as \% of the group enroled in the activity, mean values of the trial).

Este valor se aproxima do tratamento 0,75\% do PV. Fischer et al. (2002) observaram menor tempo diurno de ruminação (127 x 133 minutos) dos animais não suplementados em relação aqueles suplementados com milho em quantidade equivalente a $1 \%$ do PV, e atribuíram o fato ao maior consumo de pasto pelos animais não suplementados e à característica excludente das atividades ingestivas. Os animais não suplementados despenderam mais tempo para pastejar durante a fase diurna, o que, provavelmente, os levou a ruminar em outros horários.

Nos períodos 1 e 3, a forragem aparentemente consumida pelos animais suplementados com $0,75 \%$ do PV apresentou a maior porcentagem de FDN em relação aos demais tratamentos (Tabela 5). Diversos autores relacionaram o incremento do teor de FDN ao aumento do tempo de ruminação, pelo aumento da resistência mecânica das forragens à mastigação (Welch \& Smith, 1970; Dulphy et al., 1980; Beauchemin \& Buchanan-Smith, 1989). Durante o período 4, no qual se observou redução linear de RT, os valores extremos observados, respectivamente para o controle e 1,5\% do PV, provavelmente estão relacionados às diferenças de consumo de forragem e também ao fato de que o teor de FDN diminuiu do controle para os níveis mais elevados de suplementação (Tabela 5).

Comparando os tempos diurnos totais encontrados de pastejo e ruminação, as proporções da variável RT com relação à variável PA foram de 26, 27, 40 e $58 \%$ para os períodos 1, 2, 3 e 4, respectivamente. Considerando a suplementação, estas proporções foram de 27, 44 e 34\% de RT com relação ao PA, para o controle, e os níveis de suplementação de 0,75 e 1,5\%, respectivamente. Estes valores estão em função, principalmente, das variações na qualidade e quantidade da forragem consumida e das condições climáticas, como observado por Rovira (1996). O aumento da proporção de RT em relação ao PA pode ser atribuído à diminuição do $\mathrm{PA}$, pelo provável menor consumo dos animais suplementados, uma vez que as atividades do repertório comportamental competem entre si pela alocação do tempo despendido pelo animal (Fischer, 1996). Fischer et al. (2002) verificaram proporções RT:PA semelhantes aos do presente trabalho, de 31,1 e 38,8\%, respectivamente, para os tratamentos controle e suplementação a $1 \%$ do PV.

Apesar de a análise estatística ter sido realizada considerando os dados dentro de cada período, podese constatar o aumentos dos valores numéricos de RT 
Tabela 4 - Coeficientes de correlação entre tempo diurno de pastejo (PA), ruminação total $(R T)$, descanso total (DT), caminhada (CA), taxa de bocados (TXBOC), total bocados (TOBOC), estações visitadas (EST) e as temperaturas máxima, mínima e média $\left({ }^{\circ} \mathrm{C}\right)$

Table 4 - Correlations coefficients among diurnal time spent in grazing $(G)$ total rumination (TR), total idling $(T I)$, walking $(W)$, biting rate (BR), total bites (TB), feeding stations (FS) with maximal, minimal and mean temperatures $\left({ }^{\circ} \mathrm{C}\right)$

\begin{tabular}{lccc}
\hline $\begin{array}{l}\text { Atividade } \\
\text { Activity }\end{array}$ & \multicolumn{3}{c}{$\begin{array}{c}\text { Temperatura } \\
\text { Temperature }\end{array}$} \\
\cline { 2 - 4 } & $\begin{array}{c}\text { Máxima } \\
\text { Maximal }\end{array}$ & $\begin{array}{c}\text { Mínima } \\
\text { Minimal }\end{array}$ & $\begin{array}{c}\text { Média } \\
\text { Mean }\end{array}$ \\
\hline PA (G) & $-0,50$ & $-0,52$ & $-0,53$ \\
RT $(T R)$ & 0,62 & 0,74 & 0,66 \\
DT (TI) & NS & NS & NS \\
CA (W) & NS & NS & NS \\
TXBOC $(B R)$ & NS & NS & NS \\
TOBOC $(T B)$ & 0,42 & 0,41 & 0,42 \\
EST $(F D)$ & NS & NS & NS \\
\hline Os
\end{tabular}

Os valores correspondem aos coeficientes de correlação de Pearson $(P<0,05)$.

The values correspond to the Pearson correlation coefficients $(P<.05)$.

com o avanço da estação, correspondendo os maiores valores aos períodos 3 e 4, com 120 e 133,83 minutos respectivamente, e o menor para o período 1 , com 68 minutos. O aumento do RT pode ter sido relacionado à evolução dos teores de FDN e nível de suplemento, conforme a seguinte equação: $Y=-288,19-19,91 X_{1}+6,83 X_{2}, R^{2}=0,83$, em que $Y$ corresponde ao tempo de ruminação; $\mathrm{X}_{1}$, ao nível de suplemento; e $\mathrm{X}_{2}$, ao nível de FDN da pastagem aparentemente consumida.

O tempo diurno de descanso total (DT) apresentou comportamento quadrático em relação aos níveis de suplementação, com pontos críticos calculados de 0,45 e $1,41 \%$ do PV, respectivamente, nos períodos 1 e 4 . No entanto, nos períodos 2 e 3, DT aumentou linearmente com os níveis de suplementação. Na média geral do experimento, DT aumentou linearmente em relação aos níveis de suplementação (Tabela 2; Figura 1).

Os animais não suplementados apresentaram menores tempos de descanso, enquanto aqueles que receberam o nível de 1,5\% do PV apresentaram maior tempo diurno de descanso. Este resultado pode ser relacionado ao menor tempo de pastejo, devido ao provável menor consumo da forragem pelos animais suplementados, sobretudo no nível mais elevado de suplementação.
Fischer et al. (2002) observaram que as novilhas suplementadas com milho a $1 \%$ do PV descansaram por mais tempo que as não suplementadas, respectivamente 210 e 154 minutos. Segundo Barton et al. (1992), novilhos suplementados à tarde descansaram deitados 661 minutos, enquanto os não suplementados descansaram durante 590 minutos.

A relação entre tempo diurno de descanso e níveis de suplementação, teor de FDN da forragem aparentemente consumida e temperatura pode ser verificada pela seguinte equação: $\mathrm{Y}=255,02+59,67$ $X_{1}-4,97 X_{2}+4,96 X_{3}, R^{2}=0,89$, em que $Y$ corresponde ao tempo de descanso diurno total; $\mathrm{X}_{1}$, ao nível de suplemento; $\mathrm{X}_{2}$, ao teor de FDN da forragem aparentemente consumida; e $\mathrm{X}_{3}$, à temperatura média. A relação positiva entre o DT e o aumento do nível de suplementação provavelmente está relacionado ao aumento do aporte de nutrientes pelo suplemento e à diminuição do consumo da forragem. Por outro lado, o aumento do teor de FDN da forragem leva ao aumento do tempo de mastigação (Dulphy et al., 1980; Beauchemin \& BuchananSmith, 1989). O aumento da temperatura média leva os animais a procurar sombra e pastar ao início do dia e final da tarde (Arnold \& Dudzinski, 1978). Segundo esses autores, temperaturas próximas a $28^{\circ} \mathrm{C}$ causam estresse e diminuição no tempo diurno de pastejo, aumentando até em 77\% o tempo de descanso neste período do dia.

$\mathrm{Na}$ média geral do experimento, o tempo de caminhada variou de forma quadrática em relação aos níveis de suplementação e seu ponto crítico foi de 0,27\% do PV ou seja muito próximo do controle. Os animais do nível de 1,5\% caminharam por mais tempo durante o dia em relação aos demais, assim como durante os períodos 1, 2 e 4. Estes resultados podem estar relacionados ao aporte de nutrientes pelo suplemento no nível de $1,5 \%$, o que poderia ter contribuído para saciar os animais, diminuindo a sua intensidade de pastejo, levando-os a se deslocar mais para procurar sítios mais favoráveis de pastejo. Entretanto, estes resultados não coincidem com os observados por Restle et al. (1998), que não encontraram diferenças para CA com níveis de suplementação desde 0 até 0,45\% do PV; nem aos de Brandyberry et al. (1991), que também não encontraram diferenças no CA para animais que receberam suplementação protéica (28\%) nas estações primavera e verão. Porém, o presente resultado é semelhante aos 
registrados por Adams (1985), o qual observou que animais suplementados caminharam maiores distâncias que os não suplementados.

Nos períodos 3 e 4, a TXBOC decresceu linearmente com os níveis de suplemento, de acordo com as respectivas equações de regressão $\mathrm{Y}=52,48-9,30$ $\mathrm{X}\left(\mathrm{r}^{2}=062, \mathrm{P}=0,0001\right)$ e $\mathrm{Y}=47,99-7,95 \mathrm{X}\left(\mathrm{r}^{2}=0,94\right.$, $\mathrm{P}=0,0027)$. Considerando a média destes dois períodos, TXBOC diminuiu linearmente com a o fornecimento de níveis crescentes de suplementação de acordo com a seguinte equação: $\mathrm{Y}=50,23-8,63 \mathrm{X}$ $\left(\mathrm{r}^{2}=0,96, \mathrm{P}=0,0002\right)$.

O TOBOC foi influenciado quadraticamente $(\mathrm{P}=0,0002)$ pelos níveis de suplementação nos períodos 3 e 4, como pode ser verificado pelas equações de regressão, respectivamente $\mathrm{Y}=20615-17305 \mathrm{X}$ $+6508 \mathrm{X}^{2}\left(\mathrm{r}^{2}=0,93, \mathrm{P}=0,0008\right)$ e $\mathrm{Y}=14059-9727$ $\mathrm{X}+3226 \mathrm{X}^{2}\left(\mathrm{r}^{2}=0,94, \mathrm{P}=0,0027\right)$. Considerando a média destes dois períodos, TOBOC variou de forma quadrática. Os pontos críticos calculados foram de 1,33 e $1,5 \%$ do $\mathrm{PV}$, respectivamente nos terceiro e quarto períodos, evidenciando o decréscimo do TOBOC, à medida que aumentaram os níveis de suplementação.

As maiores TXBOC e TOBOC corresponderam ao controle, enquanto os menores valores corresponderam ao nível 1,5\%. As maiores taxas de bocados observadas para os animais controle podem ser explicadas pelo provável maior consumo de forragem e maior avidez dos animais, pois a pastagem foi sua única fonte de nutrientes. Os valores médios encontrados para TXBOC, de 50, 44 e 37 bocados por minuto, respectivamente, para os tratamentos controle, 0,75 e 1,5\% do PV, são considerados baixos para todos os tratamentos, segundo os valores de referência citados por Minson (1990), que estão entre 55 a 65 bocados por minuto. Segundo Forbes (1988), a diminuição massa de forragem promove incremento da taxa de bocados, pois à medida que aumenta a dificuldade de apreender a pastagem, o tamanho do bocado diminui. Em um mecanismo compensatório, o animal pode aumentar a TXBOC e o tempo de pastejo. Poli et al. (2001) verificaram que, à medida que a relação folha:caule diminuiu, aumentaram o tempo de pastejo e a taxa de bocados de ovinos mantidos em pastagem de azevém. O TOBOC foi maior para o controle, o que pode ser explicado pelo maior tempo de pastejo e pela maior taxa de bocados apresentados pelos animais desse tratamento.
Com relação ao número de estações alimentares visitadas por minuto (EST), não houve efeito dos níveis de suplemento sobre a resposta no período 3 e a média dos períodos 3 e 4, e o valor médio geral foi 8,07. Todavia, no período 4, EST variou quadraticamente com os níveis de suplemento, segundo a equação $\mathrm{Y}=8,38-4,07 \mathrm{X}+2,62 \mathrm{X}^{2}$ $\left(r^{2}=0,39, P=0,0178\right)$, apresentando o menor valor para o nível intermediário de suplementação. O ponto crítico calculado foi de $0,78 \%$ do PV, o que é semelhante ao nível de $0,75 \%$. O teor de FDN da pastagem disponível foi numericamente superior para os animais do T0.75 que para os demais tratamentos (Tabela 3). A qualidade inferior da pastagem provavelmente estimulou os animais a selecionar mais a forragem em cada sítio de pastejo, como pode-se supor ao verificar que as diferenças quanto ao teor de FDN da pastagem aparentemente consumida foram pequenas (Tabela 5), o que pode ter aumentado o seu tempo de permanência em cada estação alimentar. A quantidade de matéria seca verde da forragem disponível foi de 1760, 1344 e 2394 kg/ha, respectivamente, para os tratamentos controle, 0,75 e 1,5\% do PV. A menor quantidade de matéria seca verde do T0.75 pode ter dificultado mais a apreensão de forragem, prolongando o tempo de permanência nas estações alimentares.

Segundo Ruyle \& Dwyyer (1985), o comportamento ingestivo pode limitar mais a seleção da dieta que a oferta de pastagem. Os ruminantes trocam de sítio de pastejo antes da massa de forragem existente alcançar valores críticos, limitantes ao consumo, provavelmente influenciados pelas mudanças na qualidade dessa forragem. Os mesmos autores encontraram que ovinos pastando campo natural diminuíram o tempo de permanência em cada estação alimentar à medida que a massa de forragem diminuiu. Estes resultados diferem dos encontrados no presente trabalho, o que se deve, provavelmente, em parte, às diferenças de hábito de pastejo e seletividade entre as espécies avaliadas (bovinos x ovinos).

Com relação ao tempo que os animais suplementados permaneceram comendo no cocho, não se observaram diferenças entre os tratamentos, em cada período de avaliação e na média geral do experimento.

O valor observado nos primeiros dois períodos condiz com as informações na literatura (Dulphy \& Faverdin, 1987) de que o tempo de ingestão de 
Tabela 5 - Valores médios da percentagem de matéria seca (MS), cinzas, proteína bruta (PB), fibra em detergente neutro (FDN), fibra em detergente ácido (FDA), digestibilidade in vitro da matéria seca (DIVMS) e da matéria orgânica (DIVMO) da pastagem obtida através da simulação de pastejo por tratamento e por período

Table 5 - Means values of dry matter (DM), crude protein (CP), neutral detergent fiber (NDF), acid detergent fiber (ADF) percentages, in vitro digestibility of dry matter (IVDDM) and organic matter (IVDOM) of hand plucking pasture per treatment e per period

\begin{tabular}{lcccccccc}
\hline $\begin{array}{l}\text { Tratamento } \\
\text { Treatment }\end{array}$ & $\begin{array}{c}\text { Período } \\
\text { Period }\end{array}$ & MS & Cinzas & PB & FDN & FDA & DIVMS & DIVMO \\
Ash & CP & NDF & ADF & IVVDM & IVDOM \\
\hline 0 & 1 & 27,06 & 10,51 & 16,92 & 52,16 & 37,21 & 65,36 & 69,0 \\
0 & 2 & 23,56 & 9,64 & 16,25 & 55,94 & 34,65 & 66,87 & 69,79 \\
0 & 3 & 25,88 & 10,11 & 17,70 & 57,71 & 38,71 & 58,58 & 59,69 \\
0 & 4 & 35,04 & 8,44 & 11,38 & 64,54 & 37,82 & 59,83 & 61,16 \\
$0,75 \%$ & 1 & 27,96 & 11,86 & 12,69 & 58,41 & 38,42 & 58,87 & 63,54 \\
$0,75 \%$ & 2 & 27,27 & 10,02 & 18,30 & 56,88 & 34,19 & 58,65 & 60,52 \\
$0,75 \%$ & 3 & 24,18 & 8,63 & 17,58 & 62,85 & 36,24 & 66,85 & 67,88 \\
$0,75 \%$ & 4 & 36,67 & 9,66 & 10,99 & 63,10 & 38,63 & 57,77 & 58,75 \\
$1,5 \%$ & 1 & 30,73 & 15,74 & 13,71 & 53,12 & 38,26 & 55,23 & 61,01 \\
$1,5 \%$ & 2 & 26,63 & 9,80 & 16,30 & 60,33 & 39,12 & 65,38 & 67,86 \\
$1,5 \%$ & 3 & 30,16 & 8,88 & 15,60 & 64,10 & 40,07 & 68,24 & 71,23 \\
$1,5 \%$ & 4 & 37,07 & 8,01 & 10,20 & 60,74 & 41,63 & 55,19 & 55,88 \\
\hline
\end{tabular}

concentrados ou de forragem moída varia entre 10 e 25 minutos/kg de matéria seca. O aumento do valor numérico do tempo no cocho verificados nos períodos 3 e 4 com relação aos anteriores pode ser devido à inclusão de uréia no sorgo, em virtude da conseqüente diminuição da palatabilidade do suplemento (Huber \& Cook, 1972) ou da associação feita pelos animais do desconforto pelo excesso de amônia formado e o gosto da uréia (Chalupa et al., 1979). Esses autores observaram redução da taxa de ingestão nos animais suplementados com uréia. Balbinotti et al. (2002) verificaram que, em dois anos consecutivos de obser-

Tabela 6 - Médias do tempo diurno comendo no cocho (minutos)

Table 6 - Means of diurnal eating time at the trough (minutes)

\begin{tabular}{|c|c|c|}
\hline \multirow[t]{2}{*}{$\begin{array}{l}\text { Período } \\
\text { Period }\end{array}$} & \multicolumn{2}{|c|}{$\begin{array}{l}\text { Tratamentos }^{1} \\
\text { Treatments }^{1}\end{array}$} \\
\hline & T0.75 & T1.5 \\
\hline 1 & $17,5^{\mathrm{a}}$ & $29,5^{a}$ \\
\hline 2 & $20,0^{\mathrm{a}}$ & $26,0^{\mathrm{a}}$ \\
\hline 3 & $43,5^{a}$ & $58,0^{\mathrm{a}}$ \\
\hline 4 & $48,5^{\mathrm{a}}$ & $52,0^{\mathrm{a}}$ \\
\hline $\begin{array}{l}\text { Média geral } \\
\text { Overall mean }\end{array}$ & $32,4^{a}$ & $41,4^{\mathrm{a}}$ \\
\hline \multicolumn{3}{|c|}{$\begin{array}{l}\text { a Médias na linha, seguidas de letras diferentes diferem }(P<0,05) \\
\text { pelo teste } F \text {. } \\
{ }^{1} \text { T0.75 }=0,75 \% \text { do peso vivo de sorgo moído; } T 1.5=1,5 \% \text { do } \\
\text { peso vivo de sorgo moído. } \\
\text { a Means in a row followed by different letters differ }(P<.05) \text { by } F \text { test. } \\
{ }^{1} \text { To.75 = } 0.75 \% \text { of live weight of ground sorghum grain; } T 1.5=1.5 \% \text { of live } \\
\text { weight of ground sorghum grain. }\end{array}$} \\
\hline
\end{tabular}

R. Bras. Zootec., v.32, n.6, p.1408-1418, 2003 vação, a maioria dos animais consumiram até $1,5 \%$ do PV de sorgo moído em, no máximo, 60 minutos após o mesmo ser oferecido. Os autores também não encontraram diferenças quanto ao tempo de permanência no cocho entre os níveis de sorgo moído fornecidos (0,75 e 1,5\% do PV).

\section{Conclusões}

A suplementação energética fornecida a novilhos sobre uma pastagem nativa melhorada modificou o seu comportamento ingestivo. A suplementação provocou redução do tempo de pastejo e número de bocados por minuto e número de bocados totais, mas aumentou os tempos de descanso e caminhada.

\section{Literatura Citada}

ADAMS, D.C. Effect of time of supplementation on perfomance, forage intake and grazing behavior of yearling beef steers grazing Russian wildryegrass in the fall. Journal of Animal Science, v.61, n.4, p.1037-1042, 1985.

ARNOLD, G.W.; DUDZINSKI, M.C. Ethology of free-ranging domestic animals. Amsterdam: Elsevier Scientific Publishing Company, 1978. 198p.

BAILEY, P.J. Grazing behavior of steers. Proceedings of the Australian Society of Animal Production, v.10, p.303306, 1974.

BALBINOTTI, M.; PARDO, R.M.P.; FISCHER, V. et al. Efeitos de níveis crescentes de suplemento energético sobre o comportamento ingestivo no cocho de novilhos de corte em pastejo. In: REUNIÃO ANUAL DA SOCIEDADE BRASILEIRA DE ZOOTECNIA, 39., 2002, Recife. Anais ... Recife: Sociedade Brasileira de Zootecnia, 2002. CD-ROM. 
(Bioclimatologia e Etologia, 19)

BARTON, R.K.; KRYSL, L.J.; JUDKINS, M.B. et al. Time of daily supplementation for steers grazing dormant intermediate wheatgrass pasture. Journal of Animal Science, v.70, n.2, p.547-558, 1992.

BEAUCHEMIN, K.A.; BUCHANAN-SMITH, J.G. Effects of dietary neutral detergent fiber concentration and supplementary long hay on chewing acitvities and milk production of dairy cows. Journal of Dairy Science, v.72, n.9, p.2288-2300, 1989.

BRANDYBERRY, S.D.; COCHRAN, R.C.; VANZANT, E.S. Influence of supplementation method on forage use and grazing behavior by steers cattle grazing bluestem range. Journal of Animal Science, v.69, n.10, p.4128:4136, 1991.

CHACON, E.; STOBBS, T.H. Influence of progressive defoliation of a grass sward on the eating behavior of cattle. Australian Journal of Agriculture Research, v.7, n.3, p.709-727, 1976.

CHALUPA, W.; CLIFTON, A.B.; McLAUGHLIN, C.L. et al. Effect of introduction of urea on feeding behavior of Holstein heifers. Journal of Dairy Science, v.62, n.10, p.1278-1284, 1979.

CORREA, F.L. Produção e qualidade de uma pastagem nativa sob níveis de oferta de pastagem a novilhos. Porto Alegre: Universidade Federal do Rui Grande do Sul, 1993. 167p. Dissertação (Mestrado em Zootecnia) - Universidade Federal de Rio Grande do Sul, 1993.

DULPHY, J.P.; REMOND, B.; THERIEZ, M. Ingestive behavior and related activities in ruminants. In: RUCKEBUSCH, Y.; THIVEND, P. (Eds.) Digestive physiology and metabolism in ruminants. Connecticut: A.V.I. Publ. Co., 1980. p.103-122.

DULPHY, J.P.; FAVERDIN, P. L'ingestion alimentaire chez les ruminants: modalités et phénomènes associés. Reproduction, Nutrition et Dévelopment, v.27, n.1B, p.129-155, 1987.

FARINATTI, L.H.E. Desenvolvimento e comportamento ingestivo de ovinos em pastagem de azevém (Lolium multiflorum Lam.) recebendo suplementação energética ou protéica. Santa Maria: Universidade Federal de Santa Maria, 2002. 69p. Dissertação (Mestrado em Zootecnia) Universidade Federal de Santa Maria, 2002.

FISCHER, V. Efeitos do fotoperíodo da pressão de pastejo e da dieta sobre o comportamento ingestivo de ruminantes. Porto Alegre: Universidade Federal do Rui Grande do Sul, 1996. 243p. Tese (Doutorado em Zootecnia) - Universidade Federal do Rio Grande do Sul, 1996.

FISCHER, V.; MORENO, C.B.; GOMES, F.J. et al. Comportamento ingestivo diurno de novilhas jersey suplementadas com farelo de milho em pastagem de azevém (Lolium multiflorum). In: REUNIÃO ANUAL DA SOCIEDADE BRASILEIRA DE ZOOTECNIA, 39., 2002, Recife. Anais... Recife: Sociedade Brasileira de Zootecnia, 2002. CD-ROM. (Bioclimatologia e Etologia, 12)

FORBES, T.D.A. Researching the plant-animal interface: The investigation of ingestive behavior in grazing animal. Journal of Animal Science, v.66, n.9, p.2369-2379, 1988.

FORBES, J.M. Voluntary food intake and diet selection in farms animals. Wallinford: CAB International, 1995. 532p.

GONÇALVES, M.B.F. Farelo de arroz em dietas para bovinos: valor nutricional e desempenho animal. Porto Alegre: Universidade Federal do Rio Grande do sul, 2001. 228p. Tese (Doutorado em Zootecnia) - Universidade Federal do Rio Grande do Sul, 2001.

HUBER, J.T; COOK, R.M. Influence of site administration of urea on voluntary intake of concentrate by lactating cows.
Journal of Dairy Science, v.55, n.10, p.1470-1473, 1972.

IBGE. Censo Agropecuário 1995-96. Rio de Janeiro, 1998. 366p.

KARSLI, M.A. Grazing behavior of ruminant livestock. 2001. <www.agron.iastate.edu/moore/434/chapter6htm> 0405-2001.

KRYSL, L.J.; HESS, B.W. Influence of supplementation on behavior of grazing cattle. Journal of Animal Science, v.71, n.9, p.2546-2555, 1993.

MINSON, D.G. Forage in ruminant nutrition. New York: Academic Press, 1990. 483p.

MOOJEN, E.L. Dinâmica e potencial produtivo de uma pastagem nativa do Rio Grande do Sul submetida a pressões de pastejo, época de diferimento e níveis de adubação. Porto Alegre: Universidade Federal de Rio Grande do Sul, 1991. 231p. Tese (Doutorado em Zootecnia) - Universidade Federal de Rio Grande do Sul, 1991.

PARDO, R.M.P. Efeitos de níveis crescentes de suplemento energético em bezerros de corte em pastejo. Pelotas: Universidade Federal de Pelotas, 2001. 81p. Dissertação (Mestrado em Zootecnia) - Universidade Federal de Pelotas, 2001.

POLI, C.H.E.C.; ROCHS, M.G.; PIRES, C.C. et al.The effect of feed supplementation swards characteristics on the ingestive behavior of grazing ewes. In: INTERNATIONAL GRASSLAND CONGRESS, 19., 2001, Piracicaba. Proceedings.... Piracicaba: Prod. Macromedia, 2001. p.7-13.

POPPI, D.P.; HUGHES, T.P.; L'HUILLIER, P.J. Intake of pasture by grazing ruminants. In: NICOL, A.M. (ed.). Livestock production feeding on pasture. Nova Zelândia: New Zealand Society of Animal Production. Occasional Publication n.10, 1987. p.55-63.

RESTLE, J.; BACK, M.; BRONDANI, I. et al. Suplementação associada com lasalocid para novilhos em terminação em pastagem cultivada de inverno. Ciência Rural, v.29, n.3, p.555-559, 1999.

RESTLE, J.; POLLI, V.A.; EIFERT, E.C. et al. Comportamento de novilhos em pastejo horário submetidos a diferentes níveis de suplementação. In: REUNIÃO ANUAL DA SOCIEDADE BRASILEIRA DE ZOOTECNIA, 35., 1998, Botucatu, Anais...Botucatu: Sociedade Brasileira de Zootecnia, 1998, p.146-151.

ROCHA, M.G. Suplementação a campo de bovinos de corte. In: LOBATO, J.F.P. (Ed.). Produção de bovinos de corte. Porto Alegre: PUCRS, 1999. p.77-96.

ROVIRA, J. Manejo nutritivo de los rodeos de cría en pastoreo. Montevideo: Ed. Hemisferio Sur, 1996. 288p.

RUYLE, G.B; DWYER, D.D. Feedings stations of sheep as an indicator of diminished forage supply. Journal of Animal Science, v.61, n.2, p.349-353, 1985.

SAS INSTITUTE. Statistical Analysis System. Release 6.11. Cary: 1989.

WELCH, J.G.; SMITH, A.M. Forage quality and rumination time in cattle. Journal of Dairy Science, v.53, n.6, p.797800, 1970. 